\title{
Who speaks Chibrazi, the urban contact vernacular of Malawii?
}

\author{
Chimwemwe Kamanga \\ Department of Afrikaans \\ University of Pretoria
}

\begin{abstract}
Chibrazi, the urban contact vernacular of Malawi, is a mixed or hybrid variety that caricatures language contact and contact induced language change in the country. With time, the variety has evolved into an instrument of wider communication and developed in structure. Questions about the variety abound partly because the variety has not received much scholarly attention. One of such questions is: who speaks this variety? This article provides some answers to this question as obtained from a case study that was conducted as part of a research that is being conducted by the author at the University of Pretoria, which is formulated as a descriptive analysis of the variety. The data was obtained through a questionnaire, follow up interviews and observation. While the data that was obtained through the questionnaire was analysed statistically, the data from the interviews and observation was analysed thematically following the questions in the questionnaire.
\end{abstract}

Key words: Chibrazi, hybrid, language contact, Malawii, urban contact vernacular, Viphya Schools.

\section{Introduction}

Malawii is a Central African country that shares borders with Tanzania to the north and north east, Mozambique to the east and south east, and Zambia to the west. Among the many languages of the country, there is a mixed or hybrid variety that caricatures the general linguistic phenomenon of language contact. This variety is spoken in different parts across the country. From a scholarly point of view, the variety is not well known, despite its popularity. In fact, the variety has not received much scholarly attention. The situation may be attributed to the nature of the variety.

The variety does not have a particular name that is 'agreed upon' neither by the Malawiian society in general nor by its speakers. The research of which this article is part proposes that the variety should be called Chibrazi, choosing from a number of competing terms that are 
used to refer to it by various people. The term is coined by combining the Chichewa (and other Malawiian languages') prefix chi- used to denote language names, and brazi, which is a vernacularisation of the English word brother. The term brazi is one of the many address terms that male speakers of the variety use to address one another. Thus, the name Chibrazi implies [the language of brothers]. The name is an expression of the solidarity that is assumed among speakers of the variety by virtue of belonging to the same group.

Although the variety started as among a small group of people within the Malawian society, with time, the variety has evolved into an instrument of wider communication. Moto (2001), who refers to this variety as Malawi's new language, is probably the best reference in this regard. Moto $(2001,320)$ says that,

Listening to Malawian popular music and listening to the speeches of boys and girls, young men and women and sometimes older men and women in Malawi today, one is soon struck by the fact that the speeches contain words, phrases and sometimes whole sentences which sound like a foreign language. Even going through the columns of some newspapers and magazines, one soon discovers that there is a new language that has gained currency. The new language has even broken into the creative arts.

Based on Moto's assertion, it can be concluded that although Chibrazi is perceived as a 'language' of the youth, the variety is not necessarily restricted to the youth, without considering the complexity of the term youth itself.

This article further explores the question of who speaks this variety. The question is part of a research that is formulated as a descriptive analysis of the variety, which is currently in process at the University of Pretoria. The article provides answers to this question as obtained from a case study that was conducted at Viphya Schools in Northern Malawii. The data was obtained through a questionnaire, follow up interviews and observation. The data that was obtained through the questionnaire was analysed statistically. The data from the interviews and observation was analysed thematically in line with the data obtained from the questionnaire and is used mainly for purposes of corroboration. The article covers eight questions that solicited information on participants' awareness about the existence of Chibrazi; their competence and performance in the variety; their frequency of use of Chibrazi; examples of words and expressions in the variety; contexts of participants' first encounter with Chibrazi; contexts in which Chibrazi is commonly used; and the sources of Chibrazi for the participants. 


\section{What is Chibrazi?}

Chibrazi can broadly be explained as a product of language contact. This is a linguistic situation that occurs when speakers of different languages or speech varieties interact thereby bringing their respective languages into interaction as well (see Winford 2002; Holm 2000; Sebba 1997; Püitz 1994; Thomason \& Kaufman 1988; Appel \& Muysken 1987; Wardaugh 1986, 1992, and 1998 for further discussion of the concept of language contact). Scholars like these have identified various reasons for which speakers of different languages come together. For example, trade and labour. When speakers of different languages interact closely, it is typical for their languages to influence each other. That is to say that each of the languages of the groups that come into contact gets affected or influenced by the language of the other group(s) involved. In the case of Malawii, people have migrated into urban centres of the country and other countries for reasons such as employment, education and trade. This has induced the intermingling of various languages, both local and foreign, thereby creating an environment conducive for the emergence of the urban contact vernacular.

This situation is generally referred to as contact induced language change. The literature on language contact presents different types of language change that takes place depending on the degree and nature of contact; that is, depending on the influence that languages or speech varieties exert on one another. Three of these are outlined here. Perhaps the most common and most easily discernible type of language change is borrowing, the process whereby speakers of one language introduce into their language elements of another language (see Lehmann 1992 and Thomason and Kaufman 1988). Linguists have actually argued that borrowing is a necessary phenomenon for the survival of language (see for example, Fromkin 1993). The second type of language change is language shift, a situation whereby one language replaces another either in certain domains or holistically. In extreme cases, language shift might even lead to language death, a situation whereby nobody speaks the language (Crystal 2000). The third type of language change involves the creation of new languages. While Chibrazi is a new contact language, it manifests attributes of the other two types of language change as well.

The literature on contact induced language change presents an array of terminology for the new languages that are created. Some of the terms are slang, argot, code switching, youth language, hybrid language, mixed language, and urban language. In the present study, Chibrazi is said to be an urban contact vernacular. The term is borrowed from Mark Sebba's 
typology of pidgins (Sebba 1979). According to Sebba (1979), an urban contact vernacular is a type of language that seems to evolve in a particular type of urban setting, where large-scale migration from the countryside to urban areas creates poor communities that are linguistically and sometimes ethnically diverse from the mainstream communities. As a new contact language, Chibrazi is a hybrid or mixture of Malawian languages and other languages from outside the country because it combines elements from different languages. That is to say that it comprises lexemes that are coined from indigenous Malawiian languages and a vernacularisation of words from languages outside the country, which are built into the grammars of the indigenous languages. Some of the most common foreign languages from which Chibrazi derives its vocabulary are English, French, German, Portuguese, and the languages of neighbouring countries like Zambia, Zimbabwe, Mozambique, Tanzania and South Africa, just to mention some. Chibrazi also draws a lot from its counterparts in other parts of the world, especially the neighbouring countries.

This article notes some studies that have been conducted on language change in Malawi that are hereby linked to the urban contact vernacular. Most of the studies are dissertations done by students of the Chancellor College constituency of the University of Malawi. It is important to note however, that the studies cited do not accord the variety the status of urban contact vernacular or the name Chibrazi. The majority of these studies, which can be labelled as studies on language change in the Chichewa of Chancellor College, have looked at Chibrazi as a linguistic phenomenon within 'Standard' Chicheŵa. 'Standard' Chicheŵa is one of the main base languages from which Chibrazi grew and continues to grow. Below are these studies.

The first study, Tchesa (2009), investigates semantic and lexical changes in Chancellor College Chichewa by elaborating the processes through which the language is actually produced. Some of the processes that Tchesa (2009) explores are metaphoric extension, semantic broadening, semantic narrowing, semantic shift, vernacularisation, and pejoration. Tchesa (2009) observes that these processes have resulted from cultural, phonological, semantic and morphological borrowing, especially from English. Further than that, Tchesa (2009) identifies age, sex, social position or social rank, and social networks to which members belong as some of the factors that steer the change in Chancellor College Chichewa.

Nawata (2000) focuses on some of the sources of the words that constitute Chancellor College Chicheŵa. The study holds that borrowing from Chichewa and English are the major 
sources of new words for the Chancellor College student vocabulary. The fact that Nawata says that Chancellor College Chichewa borrows from Chicheŵa is interesting. It hints at the point or rather implies that the two are different languages, which is actually the point of this article as explained below. Apart from borrowing, Nawata identifies the following processes as sources of the vocabulary: clipping, de-initialisation and de-acronyming, blending, compounding, reduplication, semantic extension, semantic broadening and conversion. The study also includes bicodal expressions, idiomatic expressions, words with historical or political history, words originating from Malawian traditional practices and rituals, and onomatopoeic words as other sources of the vocabulary.

Kamowa (1994) looks at the lexical changes that have taken place in the Chichewa of Chancellor College that make it different from the original dialects of the language. The study observes that most of the lexical changes in Chancellor College Chichewa have resulted from cultural, phonological, semantic and morphological borrowing, especially from English. However, most of these borrowed lexemes have been vernacularised. The study notes that as a result of the lexical changes that have taken place in Chichewa, the "new dialect' is incomprehensible to speakers of other dialects of Chichewa, including former students of the college. This is another indication of the fact that the Chichewa of Chancellor College is a different language from Chichewa. Mutual intelligibility is one of the factors that are used to determine whether languages are dialects of the same language or not. In this case, it seems as if this is not the case.

Two other studies deserve mention here. Jalasi (1999) looks at semantic shift in Chichewa among Chancellor College students. The focus of this study is on the changes that have taken place in the meanings of some words in the dialect as applicable at the time of the research. Lekera (1994) conducts a preliminary description of the Chichewa of Chancellor College, exploring some sociolinguistic aspects of the language.

One other important study previously done on the urban contact vernacular of Malawi is Moto (2001). This paper describes what Moto refers to as Malawii's "new language" in terms of a number of aspects of the language. For instance, it briefly explores the origins of the language, its spread and its survival. It also presents a discussion of some samples of the language. Moto $(2001,320)$ describes the new language as a language that is "made up of words that are newly coined from Malawian indigenous languages and a vernacularisation of the words of some foreign languages". Moto says that the language is used as an instrument 
of establishing a social bond and identity. He regards the new language as a mirror of contemporary societal activities and attitudes, and as a manifestation of language change. Moto observes that the linguistic phenomenon that Jalasi (1999) and Lekera (1994) refer to (that is, the Chichewa of Chancellor College) is not restricted to one locality, but it applies to the country as a whole. The present study agrees with this statement and holds the opinion that it equally applies to the rest of the studies cited in this section as well.

The studies cited above show that there are two schools of thought that exist in as far as the variety under study is concerned. Firstly, the variety can be considered to be the manifestation of language change in Chichewa. This seems to be the opinion inherent in the studies of Tchesa (2009), Nawata (2000), Jalasi (1999), Kamowa (1994) and Lekera (1994). This implies that these studies look at the Chichewa of Chancellor College as one dialect or variety of Chichewa. The opinion can be said to emanate from the fact that Chichewa is the main language on which the variety under study appears to be based. In fact, for a long time, Chichewa has been the main grammatical base of the variety. This is not surprising considering that Chichewa is the national language of the country and that since its elevation to that status; it has made significant inroads into other parts of the country where it was not spoken originally (see Kamwendo 2000). However, Chichewa is not the only grammatical base that is used in Chibrazi. Other languages are also used as grammatical bases; for example Chitonga and Chitumbuka. Therefore, Chibrazi is a variety of Malawian languages in general rather than a variety of Chichewa alone.

Secondly, Chibrazi can be considered to be a language in its own right, although it utilises the grammatical structures of other languages. In this regard, the variety can be said to be a "new language' that has emerged over the years of contact among people of different ethnic groups in Malawi. This article leans more towards, and therefore subscribes to the latter school of thought, although the question of whether the variety is a language on its own is beyond the scope of this article. In light of this subscription, what Moto calls Malawi's new language and what Tchesa (2009), Nawata (2000), Jalasi (1999), Kamowa (1994) and Lekera (1994) refer to as the Chichewa of Chancellor College are considered to be essentially the same as Chibrazi. In fact, the study holds the opinion that Chibrazi can be seen to be a convergence of Malawian languages in as far as contact induced language change is concerned.

The present study is distinguished from the studies of Tchesa (2009), Nawata (2000), Jalasi (1999), Kamowa (1994) and Lekera (1994) in that the variety is treated not as a phenomenon 
exclusive to an isolated place or institution, but as a language of the whole country, a lingua franca of some kind. In addition to that, while these previous studies explore specific aspects of the urban contact vernacular of Malawii, the present study analyses the variety in a broader sense. The present study explores more aspects of the language than the previous studies. Of course Moto's study is fairly broad, but the present study adds detail to what has been explored. In addition to that, while the case study part of this research is based on one institution, like those of Tchesa (2009), Nawata (2000), Jalasi (1999), Kamowa (1994) and Lekera (1994), it targets not only learners, but all members of the institution: learners as well as staff of the various sections of the chosen institution. Therefore, the present research adds to the studies that have been conducted on Chibrazi in terms of both scope and depth.

In terms of linguistic structure, Chibrazi generally comprises three elements. The first element is referred to as core Chibrazi or pure Chibrazi. This includes vocabulary and other linguistic innovations that are created by the speakers of the variety using different language manipulation processes. These can be seen as new linguistic inventions in as far as the Malawian linguistic landscape is concerned. In other words, core Chibrazi refers to features of the variety that are unique to the variety. These strategies are generally typical of conscious language manipulation, and they reflect the provocative attitude of the speakers and their jocular disrespect of linguistic norms and purity (see Kiessling and Mous 2004). The processes through which the innovations are created can be summed up as including new coinages, loan translation, morphological manipulations, phonotactic manipulation and semantic manipulation (Kiessling and Mous 2004).

The second component of Chibrazi is what is referred to as the base language component. This is the language that supplies the grammatical structure on which Chibrazi is based. This component also includes vocabulary and other structural elements that come from the language that is used as a grammatical base of Chibrazi. Thus, there are different sub varieties of Chibrazi on the basis of base language. For instance, Chichewa based Chibrazi

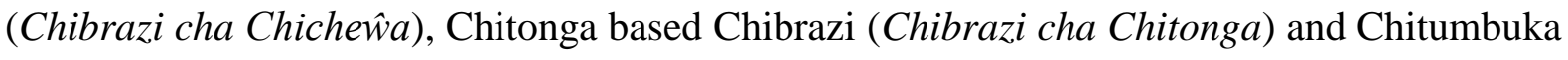
based Chibrazi (Chibrazi cha Chitumbuka), just to mention some.

The third component of Chibrazi is referred to as the source language component. This component includes vocabulary and other linguistic elements that are transferred or imported from other languages rather than the grammatical base. To this end, it can be argued that Chibrazi represents the sum total of the key players (that is, languages) in as far as language 
contact in Malawi is concerned. The base language component and the source language component are collectively referred to as the donor language component of Chibrazi. It is however, difficult to divorce Chibrazi from its donor languages because the linguistic structure of Chibrazi oscillates between the linguistic structures of its donor languages and the new inventions that are unique to the variety. The linguistic structure of Chibrazi can therefore be roughly described as a conglomeration of the linguistic structures of all its donor languages and the new inventions.

\section{Methodology}

The case study that was conducted at Viphya Schools, one of the education institutions of Northern Malawii, included a questionnaire, follow up interviews and participant and nonparticipant observation. The case study method was selected considering that it was going to be very expensive to conduct the study at a much wider scale since the variety is widespread. And, the questionnaire was selected in order to maximise the size of the population from which to draw the data. Follow up interviews and participant and non-participant observation were employed as additional techniques in order to corroborate the data drawn from the questionnaire.

Viphya Schools is located in the city of Mzuzu, which is populated by people from different parts of Malawii. For that reason, the institution was found to be a suitable place from which to draw a sample for this research. The school is a private institution that comprises a preschool, a primary school and a secondary school. As such, the sample population of the case study is of four categories: pre-school learners, primary school learners, secondary school learners, teachers of all these schools and administrative and support staff of all the schools.

At the time of the present research, there was a total population of 818 people at the three schools. This included both learners and staff of the schools, but it excluded the board of trustees of the schools. A total of 200 people had been earmarked for inclusion in the case study. The choice of 200 was not made based on any systematic consideration, but based on manageability. Because this figure is $24 \%$ of the total population of the schools; $24 \%$ of each category was to be selected to represent each of the categories of the participants in the case study. In addition to that, there would be a $50 \%$ representation of females and males. However, none of these envisaged figures materialised. Only a total of 166 subjects, that represent $20 \%$ of the total population of the schools, actually participated in the 
questionnaire. Out of these, 91 answered the questionnaire in its original form; that is, in written form. Table 1 below provides a breakdown of these participants.

Table 1: Distribution of participants in the written questionnaire

\begin{tabular}{|c|c|c|c|}
\hline Age group & Number of males & Number of females & Total \\
\hline 40 and above & 15 & 2 & $\mathbf{1 7}$ \\
\hline 30 to 39 & 3 & 3 & $\mathbf{6}$ \\
\hline 20 to 29 & 3 & 4 & $\mathbf{6 1}$ \\
\hline 10 to 19 & 47 & 14 & $\mathbf{9 1}$ \\
\hline Total & $\mathbf{6 8}$ & $\mathbf{2 3}$ & \\
\hline
\end{tabular}

The rest answered a simplified version of the questionnaire orally because the pre-test had revealed that the primary school learners were not comfortable with the written questionnaire. For this same reason, learners in pre-school were excluded from the questionnaire; they were only observed. The sample for the questionnaire was selected by means of convenient sampling because participation was voluntary.

For the interviews, the study had earmarked to select a total of 50 participants ( 25 females and 25 males) from the participants in the questionnaire also based on manageability. However, just as in the questionnaire, the reality that was found on the ground was totally different from what had been planned. Only 20 subjects volunteered to take part in the interviews.

The exact number of all the people involved in the case study of the present research is more than that presented above because of observation, about which no attempts can be made to estimate the number, considering the nature of this method. This method covered both subjects of the case study, who were mainly observed in the course of the questionnaire and the follow up interviews, and non-subjects. Every available opportunity to access Chibrazi in use was utilised. The most important times during which observations of members of the Viphya Schools' community were made was break time, after classes and week end. People were observed as they naturally interacted within the school premises as well as outside.

The data that was obtained from the questionnaire was statistically analysed with the assistance of two members of the Statistics Department at the University of Pretoria, Ms Joyce Jordaan and Ms Nina Strydom. The rest of the data was processed manually. This 
included transcribing the data from the follow up interviews and summarising the main points from the follow up interviews, and the observations.

\section{Findings}

This section presents a summary of the answers to the eight questions referred to above. The questions are explained in the course of the presentation of the findings. It is important to note that statistical analysis of the data obtained from the questionnaire is restricted to the written questionnaire. The responses from the simplified version of the questionnaire, which was answered orally and in groups, do not include figures since these were not determined. However, impressionistic analyses were made about the responses.

\section{Awareness about the existence of Chibrazi}

The first question asked whether or not participants were aware of the existence of Chibrazi. The results of this question are presented in Table 2 below.

Table 2: Awareness of the existence of Chibrazi

\begin{tabular}{|l|c|c|c|c|c|c|c|c|}
\hline \multirow{2}{*}{ Response } & \multicolumn{4}{|c|}{ Males } & \multicolumn{3}{c|}{ Females } \\
\cline { 2 - 8 } & $\mathbf{4 0}+$ & $\mathbf{3 0 - 3 9}$ & $\mathbf{2 0 - 2 9}$ & $\mathbf{1 0 - 1 9}$ & $\mathbf{4 0}+$ & $\mathbf{3 0 - 3 9}$ & $\mathbf{2 0 - 2 9}$ & $\mathbf{1 0 - 1 9}$ \\
\hline $\begin{array}{l}\text { Aware of the existence of } \\
\text { Chibrazi }\end{array}$ & 13 & 3 & 2 & 47 & 2 & 3 & 4 & 13 \\
\hline $\begin{array}{l}\text { Not aware of the existence of } \\
\text { Chibrazi }\end{array}$ & 2 & 0 & 1 & 0 & 0 & 0 & 0 & 0 \\
\hline Not attempted. & 0 & 0 & 0 & 0 & 0 & 0 & 0 & 1 \\
\hline Total & $\mathbf{1 5}$ & $\mathbf{3}$ & $\mathbf{3}$ & $\mathbf{4 7}$ & $\mathbf{2}$ & $\mathbf{3}$ & $\mathbf{4}$ & $\mathbf{1 4}$ \\
\hline
\end{tabular}

In response to this question, $95.6 \%$ of the participants; that is 87 of them, said they were aware of the existence of the language. Only 3 participants, who make up $3.3 \%$ of the respondents, said they were not aware of the existence of the language. Two of these were males in the group of 40 and above, while the other was a male in the group of 20 to 29 . It is interesting to note that some of the participants who claimed not to be aware of the existence of the variety contradicted themselves in their responses to subsequent questions in the questionnaire, which suggests that they actually know the variety. For example, they were able to provide examples of words, phrases or sentences in the variety and provide a name for 
the variety. Only one of these participants was consistent in their responses throughout the questionnaire. One female of 10 to 19 did not respond to the question.

This data shows that there are more participants who are aware of the existence of Chibrazi than those who are not. There was also a strong indication of awareness of the existence of Chibrazi from the participants who answered the questionnaire orally. The participants were able to respond to Chibrazi greetings and to explain the meanings of some words that they were asked in addition to providing examples of their own. The responses to this question can be said to be indicative of the fact that the language is very popular.

\section{Competence and performance of Chibrazi}

The fourth question asked participants about their competence and performance of Chibrazi. The participants were required to choose from five options including one that allowed them to come up with a response of their own. Table 3 summarises the results from this question.

Table 3: Competence and performance of Chibrazi

\begin{tabular}{|c|c|c|c|c|c|c|c|c|}
\hline \multirow[t]{2}{*}{ Response } & \multicolumn{4}{|c|}{ Males } & \multicolumn{4}{|c|}{ Females } \\
\hline & $40+$ & 30- 39 & $20-29$ & 10- 19 & $40+$ & 30- 39 & 20- 29 & 10- 19 \\
\hline $\begin{array}{l}\text { I speak and understand the } \\
\text { language fully. }\end{array}$ & 3 & 0 & 2 & 32 & 0 & 0 & 3 & 9 \\
\hline $\begin{array}{l}\text { I can speak the language, but I } \\
\text { do not understand it well. }\end{array}$ & 1 & 2 & 0 & 1 & 0 & 0 & 1 & 0 \\
\hline $\begin{array}{l}\text { I can understand the language, } \\
\text { but I do not speak it well. }\end{array}$ & 8 & 0 & 0 & 1 & 0 & 0 & 0 & 1 \\
\hline $\begin{array}{l}\text { I only speak and understand } \\
\text { the language a little. }\end{array}$ & 1 & 1 & 1 & 11 & 0 & 3 & 0 & 4 \\
\hline Other. & 1 & 0 & 0 & 1 & 2 & 0 & 0 & 0 \\
\hline Not attempted. & 1 & 0 & 0 & 1 & 0 & 0 & 0 & 0 \\
\hline Total & 15 & 3 & 3 & 47 & 2 & 3 & 4 & 14 \\
\hline
\end{tabular}

Forty nine participants, representing $53.8 \%$ of the participant population, stated that they speak and understand the language fluently. The majority of these, 32, were males of 10 to 19; followed by 9 females of the same age group. Eighteen of the participants, being $19.8 \%$ of the respondents, said that they only speak and understand the language a little. Twelve participants, who represent $13.2 \%$ of the participants, said that they can understand the 
language, but they do not speak it. Five participants, representing $5.5 \%$ of the respondents, said that they can speak the language, but they do not understand it well; while another 5 chose other. Two of the respondents that chose the option of other said that they do not know the language; while one simply said that they do not speak the language. Two respondents did not respond to this question.

The majority of participants in the oral version of the questionnaire also indicated that they speak and understand Chibrazi to varying degrees. The participants actually spoke the variety in the course of answering the questionnaire. The follow up interviews and observation confirmed these findings as well.

The data obtained from this question shows that while both the young people and the old people speak and understand Chibrazi, generally, there are more of the former who do so than the latter. In fact, while the majority of the older people can understand the variety, they can only speak it a little. These two extrapolations resonate with the general assertion that Chibrazi is a 'language' for the youth. It is interesting however, to see that old people are part of this variety, which confirms the assertion of Moto (2001) and the present research that the variety is currently spoken among people of varying ages.

\section{Frequency of the use of Chibrazi}

Question 5 required participants to choose the best option that describes their frequency of use of the urban contact vernacular of Malawi. The largest number of participants, 43, representing $47.3 \%$ of the participant population, indicated that they only speak the language some times. These were followed by participants who said they speak the language most of the time. There were 31 of these, representing $34.1 \%$ of the respondents. In third position were a group of 9 participants, making up $9.9 \%$ of the respondents, who pointed out that they have never spoken Chibrazi at all. Seven of these are males of 40 and above, while the other 2 are females of 40 and above. Six participants, being $6.6 \%$ of the total population, said that they have spoken the language before, but they no longer do. Five of these are males of 40 and above, while the other one is a female of 30 to 39 . The remaining $2.2 \%$ of the respondents chose other saying that they only use Chibrazi when they meet fellow speakers. Table 4 shows the details. 
Table 4: Frequency of the use of Chibrazi

\begin{tabular}{|c|c|c|c|c|c|c|c|c|}
\hline \multirow[t]{2}{*}{ Response } & \multicolumn{4}{|c|}{ Males } & \multicolumn{4}{|c|}{ Females } \\
\hline & $40+$ & 30- 39 & $20-29$ & 10- 19 & $40+$ & 30- 39 & $20-29$ & 10- 19 \\
\hline $\begin{array}{l}\text { I speak the language most of } \\
\text { the times. }\end{array}$ & 1 & 0 & 1 & 23 & 0 & 0 & 1 & 5 \\
\hline $\begin{array}{l}\text { I only speak the language } \\
\text { some times. }\end{array}$ & 2 & 3 & 2 & 23 & 0 & 1 & 3 & 9 \\
\hline $\begin{array}{l}\text { I have spoken the language } \\
\text { before, but I no longer do. }\end{array}$ & 5 & 0 & 0 & 0 & 0 & 1 & 0 & 0 \\
\hline $\begin{array}{l}\text { I have never spoken the } \\
\text { language at all. }\end{array}$ & 7 & 0 & 0 & 0 & 2 & 0 & 0 & 0 \\
\hline Other. & 0 & 0 & 0 & 1 & 0 & 1 & 0 & 0 \\
\hline Not attempted. & 0 & 0 & 0 & 0 & 0 & 0 & 0 & 0 \\
\hline Total & 15 & 3 & 3 & 47 & 2 & 3 & 4 & 14 \\
\hline
\end{tabular}

Most of the participants to whom the questionnaire was administered orally indicated that they use Chibrazi some times. Participants' responses to this question are a further indication that there are a lot of people who use Chibrazi, although there are more participants who use it seldom than those who use it often. Only few people have never spoken Chibrazi before. The data from this question also suggests that Chibrazi is more popular among the young than it is among the old. Some people used to speak the language in their youth, but they no longer do as adults. Such people can be said to have grown out of Chibrazi or outgrown it. During the interviews, one participant emphasised the point that as people grow up, they tend to 'shed off' Chibrazi.

\section{Examples of Chibrazi}

The sixth question required participants to provide five examples of words, phrases or sentences in Chibrazi. The question intended to confirm the responses that participants had provided in the preceding questions as well as the others after it and to find out what the participants' Chibrazi repertoire was like. Out of 91 participants, 82, representing $90.1 \%$ of the participant population, provided examples of Chibrazi. A whole range of words, phrases and sentences came up. The examples were all typical Chibrazi, except for those provided by one male of 30 to 39. The majority of the participants who did not provide examples of Chibrazi ( 7 out of 9) were in the group of males of 40 and above. The participants in the oral version of the questionnaire also provided a lot of examples. More examples were also 
collected in the course of the interviews and observation in this study. The examples are not included here due to shortage of space.

The answers to this question are a further indication of the participants' awareness of the existence of Chibrazi and a confirmation of the reality of their responses to other questions. The results indicate that there are differences in terms of a number of issues regarding the type of Chibrazi that different groups of people speak. For instance, the Chibrazi that boys speak is generally more offensive as it is full of obscenity, than that of girls, which is devoid of obscenity. There are also differences on the basis of age. Some of the examples are more akin to 'old School Chibrazi' (much older Chibrazi), while others are more akin to contemporary Chibrazi. However, the data does not provide any insight into the differences on the basis of other factors like mother tongue or language in general and geographical location.

\section{Contexts of first encounter with Chibrazi}

In the seventh question, participants were asked to state the place where they first came across Chibrazi. The results are summarised in Table 6.

Table 5: Contexts of first encounter with Chibrazi

\begin{tabular}{|l|c|c|c|c|c|c|c|c|}
\hline \multirow{2}{*}{ Response } & \multicolumn{4}{|c|}{ Males } & \multicolumn{3}{c|}{ Females } \\
\cline { 2 - 10 } & $\mathbf{4 0 +}$ & $\mathbf{3 0 - 3 9}$ & $\mathbf{2 0 - 2 9}$ & $\mathbf{1 0}-\mathbf{1 9}$ & $\mathbf{4 0}+$ & $\mathbf{3 0 - 3 9}$ & $\mathbf{2 0}-\mathbf{2 9}$ & $\mathbf{1 0}-\mathbf{1 9}$ \\
\hline At school. & 9 & 1 & 2 & 30 & 0 & 3 & 3 & 11 \\
\hline At home. & 2 & 0 & 1 & 7 & 2 & 0 & 0 & 1 \\
\hline At the play ground (kosewela). & 2 & 1 & 0 & 9 & 0 & 0 & 1 & 2 \\
\hline On radio. & 0 & 1 & 0 & 0 & 0 & 0 & 0 & 0 \\
\hline On television. & 1 & 0 & 0 & 0 & 0 & 0 & 0 & 0 \\
\hline Other. & 1 & 0 & 0 & 0 & 0 & 0 & 0 & 0 \\
\hline Not attempted. & 0 & 0 & 0 & 1 & 0 & 0 & 0 & 0 \\
\hline Total & $\mathbf{1 5}$ & $\mathbf{3}$ & $\mathbf{3}$ & $\mathbf{4 7}$ & $\mathbf{2}$ & $\mathbf{3}$ & $\mathbf{4}$ & $\mathbf{1 4}$ \\
\hline
\end{tabular}

The majority of the participants, 59, who represent $64.8 \%$ of the participants, claimed that they first came across the language at school. Fifteen of them, being $16.5 \%$, said that they first encountered the language at the playground, while 13 , who represent $14.3 \%$ of the total 
population, indicated the home as the place where they first came across Chibrazi. The radio and the television were each chosen by one, while another one chose the option of other, although they actually stated that they first encountered Chibrazi at home. One participant did not answer this question. These three contexts (school, playground and home) were also the most popular among the participants in the oral version of the questionnaire, although none of them clearly stood out.

The responses to this question demonstrate that different people encounter Chibrazi in different contexts. The fact that the school is the most popular domain in this regard is not surprising considering that school is one of the most central places where different people, especially the youth, meet. However, the fact that the playground and the home also appear to be important domains indicates that the variety is not far removed from its speakers. More importantly, the data from this question also shows how ubiquitous Chibrazi is.

\section{Contexts in which Chibrazi is commonly used}

Questions 8 and 9 solicited information about the contexts in which Chibrazi is commonly used. Question 8 asked subjects to indicate the contexts in which they either speak the variety if they (still) do, or where they have spoken the variety if they no longer speak it. The question asked participants to choose all applicable options providing them with five such, with the fifth one being other. It is important to note that with regard to these two questions, the choice of one option implies the denial of its counterpart.

In question 8,81 people, who are $89 \%$ of the total participant population, chose the option anywhere with friends. The option at home was chosen by 21 people, making up $23.1 \%$ of the population. The option at school with my teachers was chosen by only 7 participants, representing $7.7 \%$ of the respondents. Four participants, $6.6 \%$, chose the option of other under which the following responses came up: at the club with friends; usually where the youth meet; whenever I am with my friends, we feel it's the language that is lighter; with relatives, e.g. uncle, cousins, etc.; I don't speak this language with my parents; and any associations like games or parties. Only 3 participants chose the option at church or the mosque with religious leaders. The results of Question 8 are detailed in Table 6. 
Table 6: Contexts in which participants commonly use Chibrazi

\begin{tabular}{|l|c|c|c|c|c|c|c|c|}
\hline \multirow{2}{*}{ Response } & \multicolumn{5}{|c|}{ Males } & \multicolumn{3}{c|}{ Females } \\
\cline { 2 - 9 } & $\mathbf{4 0}+$ & $\mathbf{3 0 - 3 9}$ & $\mathbf{2 0 - 2 9}$ & $\mathbf{1 0}-\mathbf{1 9}$ & $\mathbf{4 0}+$ & $\mathbf{3 0 - 3 9}$ & $\mathbf{2 0 - 2 9}$ & $\mathbf{1 0 - 1 9}$ \\
\hline Anywhere with my friends. & 8 & 3 & 3 & 47 & 0 & 3 & 4 & 13 \\
\hline At home. & 2 & 1 & 0 & 16 & 0 & 0 & 1 & 1 \\
\hline At school with my teachers. & 1 & 0 & 0 & 5 & 0 & 0 & 0 & 1 \\
\hline $\begin{array}{l}\text { At church or mosque with my } \\
\text { religious leaders. }\end{array}$ & 1 & 0 & 0 & 0 & 0 & 0 & 1 & 1 \\
\hline Other. & 2 & 0 & 0 & 0 & 1 & 0 & 1 & 0 \\
\hline Not attempted. & 5 & 0 & 0 & 0 & 1 & 0 & 0 & 1 \\
\hline Total & $\mathbf{1 5}$ & $\mathbf{4}$ & $\mathbf{3}$ & $\mathbf{6 8}$ & $\mathbf{2}$ & $\mathbf{3}$ & $\mathbf{7}$ & $\mathbf{1 7}$ \\
\hline
\end{tabular}

In question 9, participants were asked to talk about contexts in which they have heard other people speak Chibrazi. They were also required to indicate all options that applied to them. Seventy nine participants, being $86.8 \%$ of the participants, chose the option anywhere with their friends. Thirty five subjects, who represent $38.5 \%$ of the respondents, chose the option at home. Only 8 people, who make up $8.8 \%$ of the participant population, went with the option at school with their teachers. The option at church or the mosque with their religious leaders was only chosen by 2 people. Another minority of 6 participants chose the option other. Table 7 presents the details.

Table 7: Contexts in which participants commonly hear Chibrazi

\begin{tabular}{|l|c|c|c|c|c|c|c|c|}
\hline \multirow{2}{*}{ Response } & \multicolumn{3}{|c|}{ Males } & \multicolumn{3}{c|}{ Females } \\
\cline { 2 - 9 } & $\mathbf{4 0}+$ & $\mathbf{3 0 - 3 9}$ & $\mathbf{2 0 - 2 9}$ & $\mathbf{1 0}-\mathbf{1 9}$ & $\mathbf{4 0}+$ & $\mathbf{3 0 - 3 9}$ & $\mathbf{2 0 - 2 9}$ & $\mathbf{1 0 - 1 9}$ \\
\hline Anywhere with their friends. & 13 & 3 & 3 & 42 & 1 & 2 & 4 & 11 \\
\hline At their homes. & 3 & 1 & 0 & 23 & 0 & 0 & 2 & 6 \\
\hline At school with their teachers. & 1 & 0 & 0 & 7 & 0 & 0 & 0 & 0 \\
\hline At church or mosque with & 0 & 0 & 0 & 2 & 0 & 0 & 0 & 0 \\
their religious leaders. & & & & & & & & 0 \\
\hline Other. & 0 & 0 & 0 & 5 & 0 & 1 & 0 & 0 \\
\hline Not attempted. & 1 & 0 & 0 & 2 & 1 & 0 & 0 & 2 \\
\hline Total & $\mathbf{1 8}$ & $\mathbf{4}$ & $\mathbf{3}$ & $\mathbf{8 1}$ & $\mathbf{2}$ & $\mathbf{3}$ & $\mathbf{6}$ & $\mathbf{1 9}$ \\
\hline
\end{tabular}


The responses to questions 8 and 9 clearly demonstrate that Chibrazi is mainly used between and among people that are close to each other, especially friends in different contexts that they find the language appropriate. The contexts in which the language is used are generally informal. Another point that is clear is that although the language is used at home, only few participants do so. From these observations, there is a strong indication that what determines the appropriateness of the use of Chibrazi is the relationship between or among interlocutors rather than the place where the conversation takes place. As can be seen from the data, the variety is used in different domains including the home and the school, but only when there is a close relationship between or among the speakers.

The points raised above also came out clearly from the participants in the oral version of the questionnaire, in the follow up interviews, and from observation. The learners that were interviewed also mentioned the hostels in this regard. Participants in the follow up interviews explained that the language is only used between or among friends. For example, the group of male learners that were interviewed said that they use Chibrazi during break time, which was actually witnessed during observation. Some teachers mentioned that they sometimes use the language as a strategy to 'connect' with their learners. Some of these mentioned that they even do that in the classroom, but they only do so when the environment is right. That is, when the use of Chibrazi enhances learning. Both groups of teachers agreed on the point that Chibrazi has an inherent potential of disrupting the learning process. The inappropriateness of Chibrazi in the classroom is linked to the fact that it is an anti-language by nature.

\section{Sources of Chibrazi}

Question 10 asked the subjects to provide all the sources of their knowledge of Chibrazi as at the time of the research. They were given the options television, radio, music, friends and other. The majority of the respondents, 78 , who make $85.7 \%$ of the population, indicated that friends are the source of their knowledge. Music was the second most popular source of knowledge of Chibrazi for the participants with 41 participants, being $45.1 \%$ of the respondents choosing it. Twenty subjects, representing $22 \%$ of the total population, identified the radio as a source of their present knowledge of Chibrazi. Eleven participants, standing for $12.1 \%$ of the participants, chose television as a source of their present knowledge of Chibrazi. Four people chose not to respond to this question, while 3 chose the option other. The following responses were given under the option of other: teachers, the youth, drama or 
plays, siblings, parents and other relatives, and parties, youth clubs, games and 'boys outs'. Table 8 provides the details of this question.

Table 8: Sources of Chibrazi

\begin{tabular}{|l|c|c|c|c|c|c|c|c|}
\hline \multirow{2}{*}{ Response } & \multicolumn{4}{|c|}{ Males } & \multicolumn{4}{c|}{ Females } \\
\cline { 2 - 10 } & $\mathbf{4 0}+$ & $\mathbf{3 0 -}-\mathbf{3 9}$ & $\mathbf{2 0 - 2 9}$ & $\mathbf{1 0 - 1 9}$ & $\mathbf{4 0}+$ & $\mathbf{3 0 -}$ 39 & $\mathbf{2 0 - 2 9}$ & $\mathbf{1 0 - 1 9}$ \\
\hline Television & 1 & 1 & 0 & 4 & 0 & 2 & 0 & 3 \\
\hline Radio & 2 & 2 & 0 & 11 & 0 & 0 & 1 & 4 \\
\hline Music & 5 & 2 & 1 & 23 & 0 & 1 & 1 & 8 \\
\hline Friends & 8 & 3 & 2 & 44 & 2 & 2 & 4 & 13 \\
\hline Other & 2 & 0 & 0 & 1 & 0 & 0 & 0 & 0 \\
\hline Not attempted & 3 & 0 & 0 & 1 & 0 & 0 & 0 & 0 \\
\hline Total & $\mathbf{2 1}$ & $\mathbf{8}$ & $\mathbf{3}$ & $\mathbf{8 4}$ & $\mathbf{2}$ & $\mathbf{5}$ & $\mathbf{6}$ & $\mathbf{2 8}$ \\
\hline
\end{tabular}

The data obtained from question 10 clearly shows that there are numerous sources from which different participants of the case study draw their knowledge of Chibrazi. Among these various sources, friends stand out as the most common source for both the young and the old. This point tallies with the fact that the variety is mostly used between and among people who are closely related. Music comes second. However the television and the radio do not feature as prominent sources of the variety. This is a very interesting point considering that music, which is claimed to be a source of Chibrazi by a good number of participants, is mainly popularised through the media of radio and television. This being the case, one would expect that the radio and television would be equally popular or at least close as sources of Chibrazi.

The oral version of the questionnaire yielded similar results to the ones outlined above. However, siblings and elder friends are the ones that featured more prominently than other sources. This group also included mavenda [vendors], ajigidi [mainly hip hop musicians and followers of this music genre], and marasi [Rastas, that is, people with Rastafarian traits or followers of Rastafarian music: reggae and ragamuffin]. The participants indicated that they hear mavenda speaking Chibrazi when they walk in the streets in town. It is interesting though, that for these participants, the radio and television are important sources with regard to ajigidi. They hear them on the radio and see and hear them on television. This outcome 
complicates the contradiction about music, the radio and television as sources of Chibrazi even further.

Although music, the radio and television did not feature as highly as friends in this question, the data indicates that they too are significant sources of information on Chibrazi. Perhaps one of the reasons why music, the radio and television are not as prominent as friends lies behind the level of accessibility of these sources to the participants. It can be argued that generally the participants tend to have more access to friends and relatives than to music, the radio and television due to various reasons; for example, time. Participants tend to have more time with friends than with these other sources. Another reason that might be behind this has to do with the level of interaction that is involved in the various sources of Chibrazi. It is observed in the literature on language acquisition that sources of language such as the radio and television tend to be not very effective sources of language for some people because they are dry in terms of interaction. For example, Kamanga $(2009,129)$ argues that the more interaction he gets in a particular language, the more he learns it.

\section{Conclusions}

This article sought to answer the question of who speaks the urban contact vernacular of Malawi using Viphya Schools as a case. The general conclusion that can be drawn in the article is that Chibrazi is spoken by people of different kinds at Viphya Schools. It is spoken by both males and females; the young and the old; and learners, teachers and members of the support staff of the institution. However, this conclusion ought to be sharpened in light of the differences in degrees between and within these juxtapositions of the members of the institution.

- Firstly, the young people at the institution tend to speak and understand Chibrazi better than the old. The males among these speak and understand Chibrazi better than females.

- Secondly, the young people at the institution tend to speak Chibrazi more than the old. Among these, the males tend to speak the language more than the females.

- Thirdly, the type of Chibrazi that is spoken and known by these groups of people is different across their groupings. The old tend to know and speak more of 'old school' Chibrazi, while the young know and speak more contemporary Chibrazi. Also, the 
Chibrazi known and spoken by males is more offensive than the Chibrazi known and spoken by the females of the schools.

- The fourth conclusion is that different people encounter Chibrazi in different contexts, especially places where different people converge.

- The fifth conclusion is that Chibrazi is mainly used between and among closely related people, especially friends in different contexts that they find the language appropriate.

- Finally, different members of the Viphya Schools community draw their knowledge of Chibrazi from different sources. Among these various sources, friends stand out as the most common source for both the young and the old and the males and the females.

\section{References}

Appel, R., and P. Muysken. 1987. Language contact and bilingualism. London: Edward Arnold (Publishers) Ltd.

Crystal, D. 2000. Language death. Cambridge: Cambridge University Press.

Fromkin, V. 1993. An introduction to language. $5^{\text {th }}$ ed. Texas: Harcourt Brace College Publishers.

Holm, J. 2000. An Introduction to Pidgins and Creoles. Cambridge: Cambridge University Press.

Jalasi, E. M. 1999. Semantic shift in Chichewa among Chancellor College students. B.A. Dissertation, University of Malawi.

Kamowa, O. M. 1994. Language change: A case study of language change at Chancellor College. B.A. Dissertation, University of Malaŵi.

Kamwendo, G. H. 2000. Interfacing language research with policy: The case of language in education in Malawi. Nordic Journal of African Studies 9(2): 1- 10. 
Kayambazinthu, E. L. 1995. Patterns of language use in Malawi: A sociolinguistic investigation into selected areas. PhD Thesis, La Trobe University.

Kiessling, R., and M. Mous. 2004. Urban youth languages in Africa. Anthropological Linguistics 46(3): 303- 342.

Lehmann, W. P. 1992. Historical linguistics. $3^{\text {rd }}$ ed. London: Routledge.

Lekera, C. F. 1994. Chirunga language: A preliminary description. B.A. Dissertation Zomba: University of Malawi.

Matiki, A. J. 2002. Language planning and linguistic exclusion in the legislative process in Malawi. Paper read at World Congress on Language Policies, Barcelona, 16- 20 April 2002.

Mazrui, A. M. 1995. Slang and code-switching: The case of Sheng in Kenya. A.A.P 42. pp. 168- 179.

Moto, F. 2001. Language and societal attitudes: A study of Malawi's new language. Nordic Journal of African Studies 10(2): 320- 343.

Nawata, C.A. 2000. An investigation of some possible sources of the lexical items of Malawian youth sociolects: A case study of the lexical items of the Chancellor College student sociolect. B.A. Dissertation, University of Malaŵi.

Püitz, M., ed. 1994. Language contact and language conflict. Amsterdam: John Benjamins Publishing Company.

Sebba, M. 1997. Modern linguistics: Contact languages: Pidgins and Creoles. Antony Chippenham: Rowe Ltd.

Tchesa, G. 2009. A sociolinguistic study of lexical and semantic changes in Chichewa: A case of Chancellor College. B.A. Dissertation. University of Malawii. 
Thomason, S. G. and T. Kaufman. 1988. Language contact, creolisation and genetic linguistics. Berkley: University of California Press.

Wardaugh, R. 1992. An introduction to sociolinguistics. $2^{\text {nd }}$ ed. Oxford: Blackwell.

Winford, D. 2003. An introduction to contact linguistics. Malden: Blackwell. 